\title{
Children's perceptions of weight, obesity, nutrition, physical activity and related health and socio-behavioural factors
}

\author{
Christina D Economos ${ }^{1,2, *}$, Peter J Bakun², Julia Bloom Herzog ${ }^{1}$, Peter R Dolan ${ }^{1}$, \\ Vanessa M Lynskey ${ }^{1}$, Dana Markow ${ }^{3}$, Shanti Sharma ${ }^{1}$ and Miriam E Nelson ${ }^{1,2}$ \\ ${ }^{1}$ ChildObesity 180, Friedman School of Nutrition, Tufts University, Boston, MA, USA: ${ }^{2}$ John Hancock Research \\ Center on Physical Activity, Nutrition and Obesity Prevention, Tufts University, 150 Harrison Avenue, Boston, \\ MA 02111 , USA: ${ }^{3}$ Harris Interactive, New York, NY, USA
}

Submitted 6 April 2012: Final revision received 10 August 2012: Accepted 19 September 2012: First published online 16 November 2012

\begin{abstract}
Objective: Approximately one-third of children in the USA are either overweight or obese. Understanding the perceptions of children is an important factor in reversing this trend.

Design: An online survey was conducted with children to capture their perceptions of weight, overweight, nutrition, physical activity and related socio-behavioural factors.

Setting: Within the USA.

Subjects: US children ( $n$ 1224) aged $8-18$ years.

Results: Twenty-seven per cent of children reported being overweight; $47 \cdot 1 \%$ of children overestimated the rate of overweight/obesity among US children. A higher percentage of self-classified overweight children $(81.9 \%)$ worried about weight than did self-classified under/normal weight children (31·1\%). Most children (91·1\%) felt that it was important to not be overweight, for both health-related and social-related reasons. The majority of children believed that if someone their age is overweight they will likely be overweight in adulthood (93.1\%); get an illness such as diabetes or heart disease in adulthood $(90 \cdot 2 \%)$; not be able to play sports well $(84.5 \%)$; and be teased or made fun of in school $(87 \cdot 8 \%)$. Children focused more on food/drink than physical activity as reasons for overweight at their age. Self-classified overweight children were more likely to have spoken with someone about their weight over the last year than self-classified under/normal weight children.

Conclusions: Children demonstrated good understanding of issues regarding weight, overweight, nutrition, physical activity and related socio-behavioural factors. Their perceptions are important and can be helpful in crafting solutions that will resonate with children.
\end{abstract}

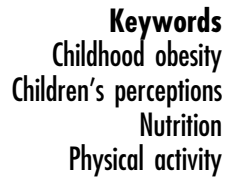

Childhood obesity is a systemic problem requiring multilevel, transdisciplinary approaches to stem the epidemic ${ }^{(1)}$. Recent data indicate that approximately one-third of children and adolescents in the USA are either overweight or obese ${ }^{(2)}$, and this represents a tripling over the past few decades. Significant disparities exist along lines of race/ethnicity ${ }^{(3)}$, income level ${ }^{(4,5)}$, geography ${ }^{(5)}$ and age ${ }^{(6,7)}$. Children from minority backgrounds, those living closer to the poverty line, those living in the southern section of the USA and older children are at greater risk for obesity. The childhood obesity epidemic is also growing globally and the prevalence of childhood overweight has increased in almost all countries in recent years ${ }^{(8)}$. While a few recent analyses indicate that childhood obesity prevalence may have peaked or even declined ${ }^{(9)}$ in the USA after years of steady increase ${ }^{(2,5,10)}$, contemporary rates of obesity remain at a dramatically high level, posing significant risks to the health of the nation's children ${ }^{(11-14)}$. As a result, the current generation may have a shorter life expectancy than their parents for the first time in history ${ }^{(13)}$. Given the stubborn nature of the condition once it is established, proactive strategies that begin early in life are needed to support prevention of becoming overweight.

Data from parents in the USA and other countries indicate that they are concerned about their children's diet, physical activity level and weight status ${ }^{(15-17)}$. Understanding parental concerns is important for effective obesity prevention interventions ${ }^{(14)}$, as parents have a unique role in promoting healthy behaviours to their children. However, children are also decision makers and are developing independent thinking when it comes to their eating and activity behaviours. Therefore, it is important to also give weight to children's views and concerns. 
A few recent studies have shed light on children's perceptions. A systemic literature review of perceptions of children in the UK showed that children focused more on the social impact of body size and weight than on health ${ }^{(18)}$. A recent study in China showed that underestimation of childhood overweight is common among both children and mothers in China, particularly for children with the highest $\mathrm{BMI}^{(19)}$. A cross-sectional study of US 14-17-year-olds based on the Youth Risk Behaviour Survey (2003) showed that children's perceived weight status is negatively associated with self-reported academic performance, regardless of actual weight status ${ }^{(20)}$. A study of thirty-six low-income 5 th grade students in one school in the US Midwest ${ }^{(21)}$ showed that students accurately perceived their weight status and that their perception of parenting strategies was significantly associated with their BMI. Another study conducted in the US Midwest of seventeen obese 8-12-year-olds demonstrated confusion about physical activity requirements and a disconnect between knowledge of healthy practices and actual health practices ${ }^{(22)}$. However, it is unclear how a large cross-section of children views the childhood obesity epidemic in terms of how it relates to short- and long-term health, self-perception, peer acceptance and society.

To have a meaningful impact on children's behaviours, and ultimately weight status, interventions and policies must be crafted with an understanding of what children feel they need, are capable of accomplishing, and have influence and control over. The objective of the present research was to survey a cross-section of US children to better understand their perceptions of weight, overweight, nutrition, physical activity and related socio-behavioural factors.

\section{Methods}

Harris Interactive (a leading market research firm) was commissioned by child obesity researchers at Tufts University to conduct an online survey containing a series of seventeen questions focused on weight, nutrition and physical activity in January 2010 within the USA. Survey questions were fielded as part of a larger survey of US 8-18-year-olds covering a range of topics. The sample was obtained from the Harris Poll Online (HPOL) opt-in panel of millions of respondents. Invitations for the HPOL panel were emailed to a stratified random sample identified as US residents aged 13-18 years and to a stratified random sample identified as US residents aged 18 years or older with a 8-17-year-old child in the household. Respondents were invited through password-protected email invitations to participate in the survey. The HPOL panel was recruited through hundreds of sources using diverse recruitment methods in order to minimize selection bias.

Among 1258 US children aged 8-18 years surveyed, thirty-four surveys from children who were not attending school were excluded. The resulting 1224 surveys were split into two groups: tweens (8-12 years, $n$ 479) and teens (13-18 years, $n$ 745). Standard demographic information was collected. Figures for age, gender, race/ethnicity, parental education, urbanicity and region were weighted where necessary to bring them into line with their actual proportions within the population.

Questions were designed by childhood obesity researchers. Careful and intentional wording was used due to the sensitive nature of the topic. The questions covered areas of interest including self-assessment of weight; percentage of US children they believed to be overweight; why is it important/not important for a young person to not be overweight; how much worry is associated with being overweight, not having enough money, doing well in school, being hurt in a car accident or getting heart disease or diabetes; whether young people understand the consequences of overweight; why overweight is occurring in kids; what they felt adults should know to help people their age be a healthy weight; and whether they had talked with anyone about how to achieve a healthy weight or how not to be overweight (e.g. parent, friend, doctor, teacher).

There were twelve opinion-type questions with 4- or 5-point Likert scale responses ('very likely' to 'not likely at all'; 'a lot' to 'not at all'), three multiple choice questions representing what children likely know/believe and two open-ended questions allowing write-in options. Likert scale responses were re-coded to binary due to small cell values at the outer limits of the scale. Children were asked to provide a self-assessment of their own weight status by selecting one of five possible response options: 'very overweight', 'slightly overweight', 'about right weight', 'slightly underweight' and 'very underweight'. These responses were re-coded to 'overweight' and 'under/normal weight'. Quotes from responses to open-ended questions were edited for typing errors and spelling when necessary. However in an effort to capture the ways in which children express themselves, grammar was not corrected.

Frequencies for all survey response categories are reported. Further, response differences between categories of overweight children and under/normal weight children, race/ethnicity, parental education, urbanicity and region were compared using Pearson's $\chi^{2}$ test. Significance levels, where appropriate, were set at $P \leq 0 \cdot 05$. Analyses were done using SAS version $9 \cdot 2$.

The study was conducted according to the guidelines laid down in the Declaration of Helsinki and all procedures involving human subjects were reviewed and approved by the Tufts University Institutional Review Board according to standard procedures.

\section{Results}

\section{Demographics}

Table 1 summarizes the demographics of the study population. Unweighted and weighted percentages are 
shown for age, gender, race/ethnicity, parental education, urbanicity and region.

\section{Estimate of own weight status and national trends}

Table 2 shows data on children's self-assessment of their own weight status. When asked to categorize themselves, $27 \cdot 0 \%$ of children $(21 \cdot 3 \%$ of tweens and $31 \cdot 4 \%$ of teens) reported being overweight. This compares with a national rate of $34.7 \%$ of 6-19-year-olds with BMI at or above the 85th percentile, based on the most recent National Health and Nutrition Examination Survey (NHANES) data ${ }^{(2)}$.

When asked to give an estimate of what percentage of children in the USA are overweight (Table 3), $42.9 \%$ had an accurate estimation that approximately one-third of US children are overweight. However a similar proportion $(47 \cdot 1 \%)$ overestimated, thinking that half or more of US children are overweight.

Table 1 Survey participants' demographics: US children ( $n$ 1224) participating in an online survey, January 2010

\begin{tabular}{lcc}
\hline Variable & Unweighted (\%) & Weighted (\%) \\
\hline Gender & & \\
Male & $48 \cdot 0$ & $50 \cdot 6$ \\
Female & $52 \cdot 0$ & $49 \cdot 5$ \\
Age & $39 \cdot 1$ & \\
8-12 years (tweens) & $60 \cdot 9$ & $43 \cdot 6$ \\
13-18 years (teens) & & $56 \cdot 4$ \\
Race/ethnicity & $9 \cdot 6$ & $18 \cdot 7$ \\
Hispanic & $8 \cdot 8$ & $14 \cdot 8$ \\
Black/African American & $68 \cdot 6$ & $57 \cdot 8$ \\
White & $13 \cdot 0$ & $8 \cdot 7$ \\
Other & $19 \cdot 7$ & $19 \cdot 7$ \\
Region & $31 \cdot 1$ & $34 \cdot 1$ \\
$\quad$ East & $25 \cdot 7$ & $21 \cdot 9$ \\
South & $23 \cdot 5$ & $24 \cdot 0$ \\
Midwest & & \\
West & $26 \cdot 9$ & $28 \cdot 7$ \\
School location & $38 \cdot 9$ & $45 \cdot 4$ \\
$\quad$ Urban & $30 \cdot 6$ & $22 \cdot 2$ \\
Suburban & $3 \cdot 6$ & \\
Rural & & \\
$\quad$ Not reported & $13 \cdot 8$ & $27 \cdot 4$ \\
Parent education level & $73 \cdot 8$ & $60 \cdot 9$ \\
$\quad$ SHigh school & $12 \cdot 4$ & \\
> High school & & \\
Not reported & & \\
\hline
\end{tabular}

\section{Topics of worry}

Table 4 shows the responses of children to five separate questions about things that might be worrisome to them, stratified by self-categorized weight status. Among the questions asked, the highest percentage of children who self-categorized as under/normal weight reported worrying about doing well in school $(64 \cdot 4 \%)$ or having enough money $(64 \cdot 4 \%)$. High percentages of children who self-categorized as overweight also worried about school $(75 \cdot 2 \%)$ and money (78.2\%). However, when asked how worried they were about being or becoming overweight there was a large difference between children who self-categorized as overweight and those selfcategorized as under/normal weight, with $81.9 \%$ of self-categorized overweight children reporting worrying compared with $31 \cdot 1 \%$ of self-classified under/normal weight children. Similar trends were found when the responses from tweens and teens were separated. Therefore among the questions asked, weight status was the top worry to children who considered themselves overweight.

\section{Importance of not being overweight and consequences of overweight}

When asked how important it is for a person of their age to not be overweight, $91 \cdot 1 \%$ of children responded that it was somewhat important or very important. When children who chose somewhat/very important were asked why it is important for a person their age to not be overweight, both health-related and social-related reasons were given to this open-ended question. Examples of health-related quotes:

'Because being overweight at any age isn't good. If you eat too much and don't exercise now those bad habits may stick with you' (9-year-old female).

'first, if you're already overweight, you have chances of getting diabetes. second, you could get heart diseases and you could not live as long as a healthy person' (10-year-old female).

'Might get Diabetes' (11-year-old male).

'because it can lead to other health problems that may lead to death' (12-year-old male).

Table 2 Children's self-assessment of own weight status; US children ( $n$ 1224) participating in an online survey, January 2010

Question: 'Do you think you are...?'

\begin{tabular}{lccc}
\hline Estimate of own weight status & $\begin{array}{c}\text { Total (tweens and teens) } \\
(\%)\end{array}$ & $\begin{array}{c}\text { Tweens } \\
(\%)\end{array}$ & $\begin{array}{c}\text { Teens } \\
(\%)\end{array}$ \\
\hline Overweight $^{*}$ & $27 \cdot 0$ & $21 \cdot 3$ & $31 \cdot 4$ \\
Under/normal weightt & 73.0 & 78.7 & 68.6 \\
\hline
\end{tabular}

Tweens, aged 8-12 years; teens, aged 13-18 years.

${ }^{*}$ Response options were: 'slightly overweight', 'very overweight'.

tResponse options were: 'very underweight', 'slightly underweight', 'about the right weight'. 
Table 3 Children's estimation of the national rate of overweight/obesity; US children ( $n$ 1224) participating in an online survey, January 2010 Question: 'How many of the kids in the US are overweight?'

\begin{tabular}{lccr}
\hline Estimate of overweight in USA & $\begin{array}{c}\text { Total (tweens and teens) } \\
(\%)\end{array}$ & $\begin{array}{c}\text { Tweens } \\
(\%)\end{array}$ & $\begin{array}{c}\text { Teens } \\
(\%)\end{array}$ \\
\hline$\leq 10 \% *$ & $10 \cdot 0$ & $17 \cdot 0$ & $4 \cdot 6$ \\
$33 \%$ & $42 \cdot 9$ & $38 \cdot 8$ & $46 \cdot 1$ \\
$\geq 50 \%+$ & $47 \cdot 1$ & $44 \cdot 2$ & $49 \cdot 3$ \\
\hline
\end{tabular}

Tweens, aged 8-12 years; teens, aged 13-18 years.

*Response options: ' $5 \%$ ', '10\%'.

tResponse options: '50\%', '60\%'.

Table 4 Topics that are a worry to children; US children ( $n$ 1224) participating in an online survey, January 2010 *Questions: 'How worried are you about...?'

\begin{tabular}{|c|c|c|c|c|c|}
\hline & $\begin{array}{l}\text { Weight } \\
(\%) \dagger\end{array}$ & $\begin{array}{c}\text { School } \\
(\%)+\end{array}$ & $\begin{array}{c}\text { Money } \\
(\%)+\end{array}$ & $\begin{array}{l}\text { Car accident } \\
(\%) \dagger\end{array}$ & $\begin{array}{c}\text { Diabetes/heart disease } \\
(\%) \dagger\end{array}$ \\
\hline \multicolumn{6}{|l|}{ Total (tweens and teens) } \\
\hline Self-categorized as overweightł & $81 \cdot 9$ & $75 \cdot 2$ & $78 \cdot 2$ & $40 \cdot 8$ & $49 \cdot 5$ \\
\hline Self-categorized as under/normal weight $\S$ & $31 \cdot 1$ & $64 \cdot 4$ & $64 \cdot 4$ & $41 \cdot 1$ & $33 \cdot 8$ \\
\hline \multicolumn{6}{|l|}{ Tweens } \\
\hline Self-categorized as overweightł & $74 \cdot 6$ & $77 \cdot 2$ & $59 \cdot 6$ & $30 \cdot 7$ & $35 \cdot 1$ \\
\hline Self-categorized as under/normal weight§ & $24 \cdot 3$ & $59 \cdot 8$ & $52 \cdot 6$ & $36 \cdot 4$ & $23 \cdot 3$ \\
\hline \multicolumn{6}{|l|}{ Teens } \\
\hline Self-categorized as overweightł & $85 \cdot 7$ & $74 \cdot 2$ & $88 \cdot 0$ & $46 \cdot 1$ & $57 \cdot 1$ \\
\hline Self-categorized as under/normal weight\$ & $37 \cdot 2$ & $68 \cdot 5$ & $74 \cdot 8$ & $45 \cdot 2$ & $43 \cdot 1$ \\
\hline
\end{tabular}

Tweens, aged 8-12 years; teens, aged 13-18 years.

*Five separate questions: 'How worried are you about being or becoming overweight?'; 'How worried are you about doing well in school?'; 'How worried are you about not having enough money?'; 'How worried are you about being hurt in a car accident?'; 'How worried are you about getting an illness such as diabetes or heart disease?'.

tThe scale was dichotomized into 'worried'/'not worried' and only the percentages for those who worried are shown here.

‡'Slightly overweight' or 'very overweight' selected in self-assessment.

$\S$ 'Very underweight', 'slightly underweight' or 'about the right weight' selected in self-assessment.

'1.diabetes 2.bad on physical health 3.slows you down' (14-year-old female).

'I believe that as growing teenagers, we should watch what we eat. Our bodies are still developing, so many diseases can come and destroy our bodies easily. So be healthy!' (15-year-old female).

'im young ... being overweight will just make getting older harder to do healthily' (17-year-old male).

Examples of social-related quotes:

'Because the other kids tease you if you are which makes for a long day' (9-year-old male).

'Because if you are overweight kids look at you differently and they treat you differently' (10-yearold female).

'because you are fat and slow and put most of your energy into exercising instead of issues or problems or school' (11-year-old male).

'if you are fat you get picked on and people are mean to you' (14-year-old male).

In response to four separate questions about the likelihood of a particular consequence if someone their age is overweight, the overwhelming majority of children reported that if someone their age is overweight they will likely be overweight in adulthood (93.1\%); they will likely get an illness such as diabetes or heart disease in adulthood (90.2\%); they will not be able to play sports well $(84.5 \%)$; and they will be teased or made fun of in school $(87 \cdot 8 \%)$.

\section{Reasons for overweight}

Figure 1 shows responses of children when asked to choose three out of ten possible reasons why some people at their age are overweight. Of the choices provided, eating or drinking too much sugar, candy or soda ( $70 \cdot 4 \%$ of tweens, $64 \cdot 2 \%$ of teens); consuming too much food $(56 \cdot 9 \%$ of tweens, $47 \cdot 8 \%$ of teens); and consuming food with too much fat $(48 \cdot 7 \%$ of tweens, $52 \cdot 5 \%$ of teens) were the top three selections.

When asked an open-ended question about what adults need to know to help people their age to be a healthy weight, $41 \cdot 6 \%$ of children gave food/nutritionbased responses, $9 \cdot 2 \%$ gave physical activity-related responses and $19 \cdot 4 \%$ gave responses involving both food and physical activity; $20.0 \%$ of responses involved neither nutrition nor physical activity; and 9.7\% were ambiguous or non-responses. Teens in general provided 


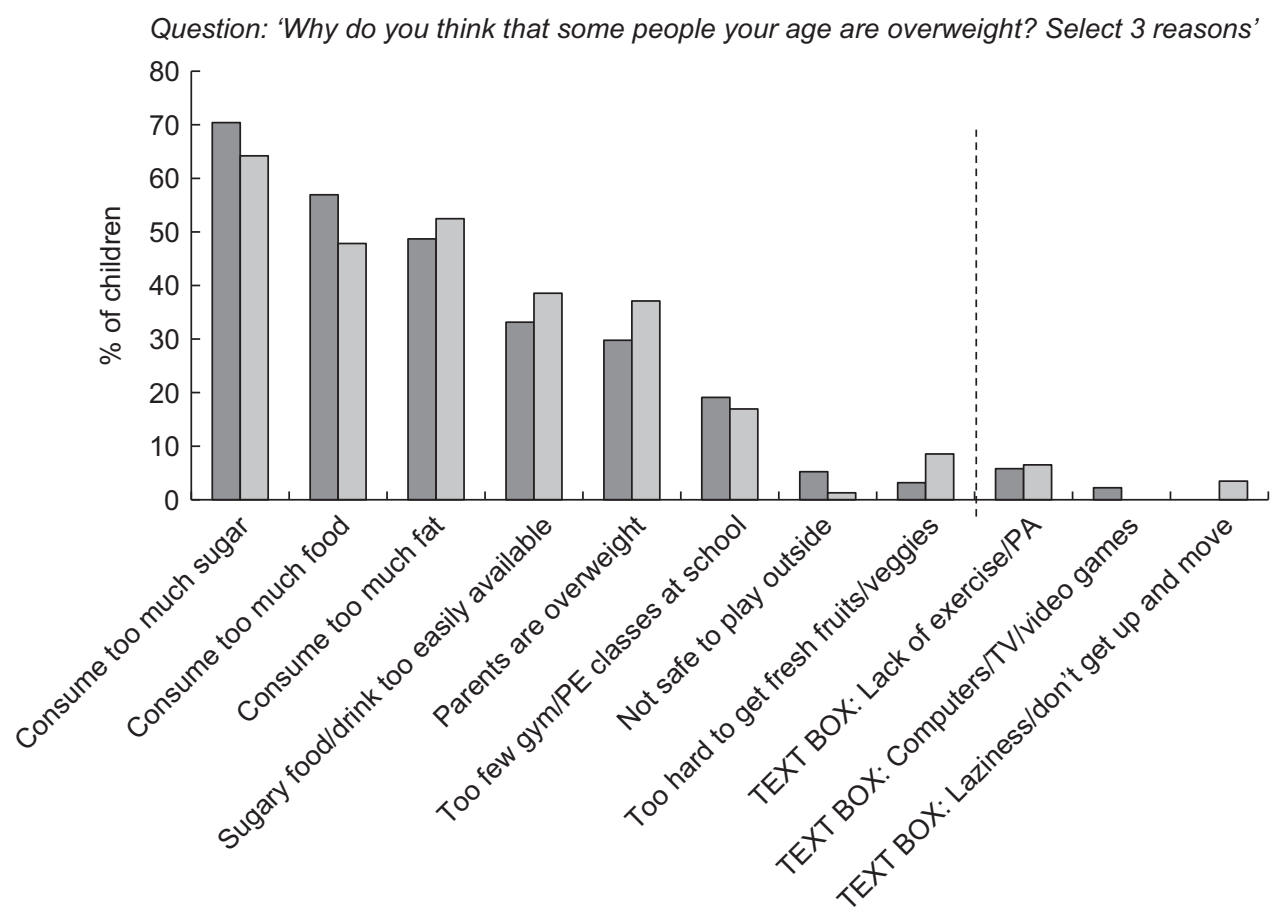

Fig. 1 Children's opinions on why some people of their age are overweight; US children ( $n$ 1224) ( $\square$, tweens, aged 8-12 years; $\square$, teens, aged 13-18 years) participating in an online survey, January 2010. Children were asked to select three reasons that are important. The choices were: 'it's not safe for them to walk or play outside'; 'they don't have enough gym or PE classes at school'; 'they eat or drink too much sugar, candy or soda'; 'they eat or drink food that has too much fat'; 'they eat or drink too much food'; 'their parents are overweight'; 'it's too easy to get foods and drinks with lots of sugar'; 'it's too hard to get fresh fruits and vegetables'; 'something else (TEXT BOX)'; and 'I don't know'. 'Lack of exercise/PA'; 'prefer computers/TV/video games'; and 'laziness/don't get up and move' were coded categories of 'something else (TEXT BOX)' responses. (Abbreviations: PE, physical education; PA, physical activity; TV, television)

more specific responses than tweens, as would be expected based on maturity level. Some examples of responses:

'to teach us not to eat too much like my mom does. fruit instead of candy, junk food only once in a while' (8-year-old male).

'Make sure they know the best foods to eat and how to play with us so we exercise' (8-year-old male).

'We need to eat more fresh meats, fruits and vegetables. Chicken fingers and french fries are easy to make but very unhealthy. We also need to drink more water and less juice or soda' (10-year-old female).

We need lots of exercise/play time. That we need to eat balanced amounts of food - not too much of any type of food. Also, having a loving relationship with kids help in how they see themselves' (11-year-old female).

'They need to know how to make exercising fun and exciting so people my age that are overweight will be more willing to exercise' (13-year-old female).

'be smart when buying groceries for the family and know what is in the food you are giving your kids' (15-year-old male).
'They need to know what a healthy weight is. They need to have a better understanding of nutrition. They need make their kids exercise' (16-year-old female).

\section{Discussions about weight issues}

Figure 2 shows responses to the question 'During the past year, have you had a serious discussion with any of the following people about how you can be a healthy weight and not be overweight?' More than one selection could be made in response to this question. Self-categorized overweight tweens and self-categorized overweight teens were more likely to have spoken with someone about their weight over the last year than self-categorized under/ normal weight tweens and teens, with only $21.9 \%$ of overweight tweens and $34.6 \%$ of overweight teens saying that they spoke to no one, compared with $57 \cdot 1 \%$ of under/ normal weight tweens and $56.0 \%$ of under/normal weight teens. Self-categorized overweight tweens spoke most often with their mothers (57.9\%) and self-categorized overweight teens spoke most often with their friends and others of similar age $(67 \cdot 7 \%)$. A significant proportion of self-categorized overweight teens $(40 \cdot 1 \%)$ also spoke to their mothers. There was also some communication with doctors/nurses $30.7 \%$ of self-categorized overweight 
Question: 'During the past year, have you had a serious discussion with any of the following people about how you can be a healthy weight and not be overweight?

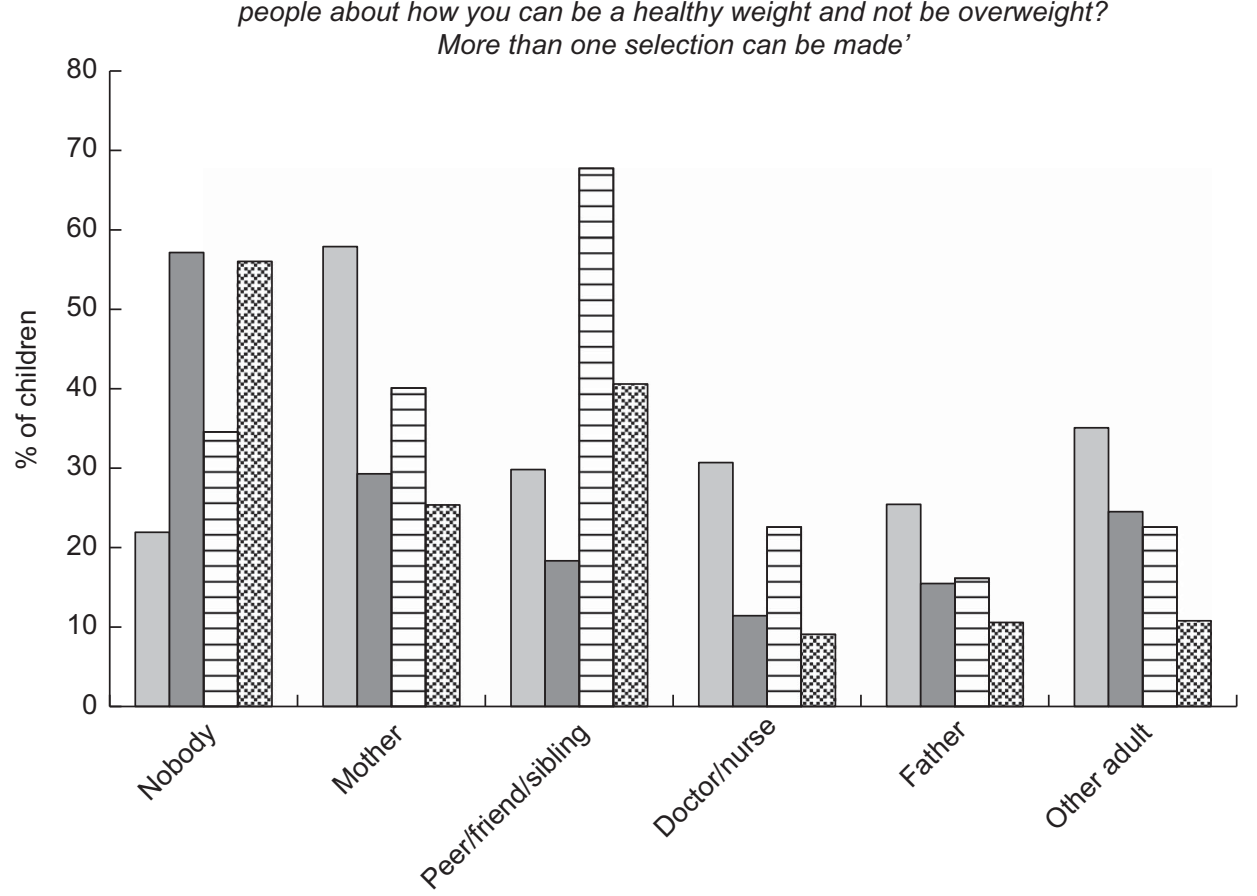

Fig. 2 People with whom children have discussed weight issues; US children ( $n$ 1224) ( $\square$, tweens (aged 8-12 years) selfcategorized as overweight*; $\square$, tweens self-categorized as under/normal weight $\dagger$; 目, teens (aged 13-18 years) self-categorized as

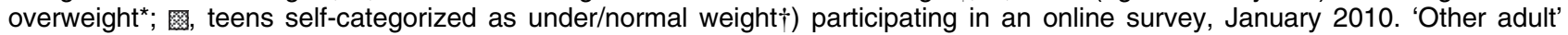
included teachers and excluded parents, doctors and nurses. 'Peer/friend/sibling' included separate selection of 'peer', 'friend', 'sibling' or 'another person your age' (*'slightly overweight' or 'very overweight' selected in self-assessment; †'very underweight', 'slightly underweight' or 'about the right weight' selected in self-assessment)

tweens; $22 \cdot 6 \%$ of self-categorized overweight teens) and other adults $(35 \cdot 1 \%$ of self-categorized overweight tweens; $22 \cdot 6 \%$ of self-categorized overweight teens). Of the selfcategorized overweight children who did speak with someone, a high proportion (66.5\% for tweens and $70 \cdot 2 \%$ for teens) reported speaking with more than one person.

\section{Analyses based on demographics}

Analyses of survey data based on race/ethnicity, parental education and urbanicity showed no significant differences. There was a regional difference with respect to self-categorized weight status, with a higher proportion (40\%) of children in the southern part of the USA reporting being overweight compared with other regions (18\% East, 22\% Midwest, 20\% West).

\section{Discussion}

This cross-sectional sample of US children demonstrated concern and were knowledgeable about issues regarding weight, overweight, nutrition, physical activity and related socio-behavioural factors.

When asked to categorize themselves, $27 \cdot 0 \%$ of children reported being overweight. This compares with a national rate of $34.7 \%$ of $6-19$-year-olds with BMI at or above 85th percentile, based on the most recent NHANES data ${ }^{(2)}$. This finding is in line with those reported in a recent study of seventeen obese 8-12-year-olds in the US Midwest in which $42 \%$ of these overweight children reported that they were underweight or normal weight ${ }^{(22)}$. Similar trends have been reported internationally, as demonstrated by a study in China showing that underestimation of childhood overweight is common among both children and mothers in China, particularly for children with the highest $\mathrm{BMI}^{(19)}$, and a European study ${ }^{(23)}$ showing that overweight children were less able than normal weight children to correctly assess their own body weight. In the present study $42.9 \%$ of the children had an accurate estimation that approximately one-third of US children are overweight. However, a similar proportion $(47 \cdot 1 \%)$ overestimated, thinking that half or more of US children are overweight. The high percentage of children who overestimated the national rate of overweight, along with self-assessment of overweight at lower than the national rate, may reflect a shift in cultural weight norms among today's children and may be an indication that they see themselves as smaller than their peers or the population around them. A recent study in Italy showed that higher regional obesity prevalence was associated with lower maternal perception of their child's weight status, suggesting that what is common has a greater likelihood of being perceived as normal ${ }^{(24)}$. A similar shift 
in perception of weight status among US children may explain the findings reported here. Such changes in cultural weight norms and perceptions must be considered when crafting strategies to address the issue of childhood obesity.

A high percentage of children, both those who selfcategorized as overweight and under/normal weight, reported worrying about doing well in school and about having enough money. However, when asked how worried they were about being or becoming overweight there was a large difference between children who selfcategorized as overweight and those self-categorized as under/normal weight, with $81.9 \%$ of self-categorized overweight children reporting worrying compared with $31 \cdot 1 \%$ of self-classified under/normal weight children. These results are consistent with a study of Scottish 15 -year-olds in which worrying about weight was also found to be more prevalent among obese children ${ }^{(25)}$ and a study in Germany showing that obese children and adolescents had more weight concerns than their normal weight counterparts ${ }^{(16)}$. Therefore there are similar concerns in the USA and other countries, and weight status is a significant worry and an additional burden borne by children who consider themselves overweight or obese.

Children overwhelmingly agreed (91.1\%) that it was important to not be overweight at their age and gave both health-related and social-related reasons in open responses. This is in contrast to a literature review performed in the UK which reported that children focused on the social impact of body size rather than health issues ${ }^{(18)}$. The overwhelming majority of children reported that if someone their weight is overweight they will likely be overweight in adulthood; they will likely get an illness such as diabetes or heart disease in adulthood; they will not be able to play sports well; and they will be teased or made fun of in school. A recent study of 1555 adolescents at two high schools in Connecticut also reported that youth perceive frequent and multiple forms of weight-based victimization ${ }^{(26)}$. The findings reported here show that children have a clear understanding of the long- and short-term negative consequences of being overweight, both now and in the future as adults. This understanding is perhaps the result of public health education and regular exposure to health-related claims and advertising, such as claims associated with food advertising. The findings highlight the potential for children to be an important part of crafting and executing solutions, given that they clearly understand and worry about the long-term implications of being overweight.

When asked to choose three of ten possible choices, children selected eating or drinking too much sugar, candy or soda; consuming too much food; and consuming food with too much fat as the top three reasons for overweight at their age. These food-related choices ranked ahead of parents being overweight or the two physical activityrelated options provided (not enough gym or physical education classes at school; not safe to walk or play outside).
However one limitation of this question is that a broader physical activity-related response such as 'lack of exercise/physical activity' was not one of the choices provided. Children who entered a response that was coded as 'lack of exercise/physical activity' had to select 'something else' and write into the text box. It is possible that 'lack of exercise/physical activity' would have been one of the top three reasons selected if the choices were presented differently. Responses to an open-ended question about what adults need to know to help people their age to be a healthy weight also focused more on food/nutrition than on physical activity. These perceptions are in line with studies showing that in adolescents, increase in moderate physical activity was not associated with change in weight status ${ }^{(27)}$, possibly due to increased dietary intake or body composition changes in response to physical activity ${ }^{(27,28)}$. However, an increase in highintensity physical activity was effective in reducing body fat, although not $\mathrm{BMI}^{(28)}$. National data suggest that a wide range of strategies, including modifications in dietary intake and physical activity, can be utilized in reducing the imbalance in energy intake and expenditure (energy gap) associated with weight gain ${ }^{(29)}$. The findings reported here show that although children have an understanding of the importance of dietary intake and physical activity in maintaining a healthy weight, there is an opportunity for increased education and awareness of energy balance, and the role of both dietary intake and physical activity.

Children who self-categorized as overweight were more likely to have spoken with someone about their weight over the last year than those who self-categorized as under/ normal weight. When they did speak with someone, self-categorized overweight tweens spoke most often with their mothers and self-categorized overweight teens spoke most often with their friends and others of similar age. This is in line with the greater importance placed on peer relationships as children move into teenage years. In addition a significant proportion of self-categorized overweight teens also spoke with their mothers, underscoring mothers' unique role in promoting healthy eating and activity behaviours to their children ${ }^{(14)}$. There was also communication with doctors/nurses and other adults. A high proportion of self-categorized overweight children reported speaking with more than one person about their weight issues over the last year. Therefore children who see themselves as overweight are discussing the issue with trusted individuals, providing opportunities for effective intervention and further underscoring the increased burden borne by overweight children. A recent analysis of NHANES data ${ }^{(30)}$ showed that less than one-quarter of parents of overweight children reported having been told by their health-care professional that their child is overweight. In addition the choice of terminology used by health-care providers when communicating about children's weight and obesity plays a role in effective 
motivation to lose weight ${ }^{(31)}$. Therefore the individuals with whom children are speaking need to be well informed and to communicate effectively about the issues.

Analyses of data by race/ethnicity, parental education and urbanicity showed no significant differences. It is possible that differences in weight status did not show up in these analyses partly because weight was self-reported. However, when analysed based on geographic region, a higher proportion of children in the southern part of the USA reported being overweight compared with other regions. This is in line with national data showing the highest obesity rates in the southern part of the USA ${ }^{(5)}$.

Limitations of the present study that must be taken into consideration include the fact that while every effort was made to craft questions carefully, there is the possibility that question design may have influenced responses. In addition, surveys were conducted online and there was no way to ensure that responses were those of children alone and not influenced by parents. To be part of the study an email address was needed and access to a computer, although not necessarily a home computer. Participants could complete the survey at a computer away from the home, e.g. at a public library. In spite of this, online sampling may result in lesser representation from lower-income children who do not have Internet access in the home. While a telephone survey may have generated a more random sample than the online survey, telephone surveys also have limitations such as higher representation of those with land-line telephones in their homes and lower response rates. Telephone surveys are also not age-appropriate, as questions and response options read over the telephone may be more difficult for a child to follow than written questions and response options. Many parents are also reluctant to allow their children to participate in telephone surveys.

Children typically do not participate in large-scale decisions that affect their well-being, which may explain why some past obesity prevention efforts have been unsuccessful. There is a definite lack of studies that capture opinions and concerns of a large cross-section of children about weight, overweight, nutrition and physical activity issues $^{(18)}$; hence the value and importance of the data presented in the current study. Data reported here show that children have a good understanding of issues regarding weight, overweight, nutrition, physical activity and related socio-behavioural factors. Adding their voices to the evidence base will allow children to have an influence over future policies, interventions and treatment decisions. The incorporation of these data into decision-making processes will help organizations to develop and tailor appropriate programmes.

\section{Acknowledgements}

The study was commissioned by ChildObesity180, a multi-sector group of senior-level national leaders working together to create a coordinated and integrated set of strategies to reverse the trend of childhood obesity on a national level. Source of funding: The study was funded with support from the Robert Wood Johnson Foundation (grant number 66672). Conflicts of interest: The authors have no conflicts of interest. Authors' contribution: C.D.E contributed to study design, data interpretation and writing. P.J.B. contributed to data analysis, data interpretation and writing. J.B.H. contributed to study design and writing. P.R.D. contributed to study design and writing. V.M.L. contributed to study design and writing. D.M. contributed to study design, data analysis and writing. S.S. contributed to data analysis, data interpretation and writing. M.E.N. contributed to study design, data interpretation and writing. Acknowledgements: The authors would like to thank Margaret Maruschak for her thoughtful contribution to the development of the survey questions.

\section{References}

1. Huang TT, Drewnosksi A, Kumanyika S et al. (2009) A systems-oriented multilevel framework for addressing obesity in the 21st century. Prev Chronic Dis 6, A82.

2. Ogden CL, Carroll MD, Kit BK et al. (2012) Prevalence of obesity and trends in body mass index among US children and adolescents, 1999-2010. JAMA 307, 483-490.

3. Skelton JA, Cook SR, Auinger P et al. (2009) Prevalence and trends of severe obesity among US children and adolescents. Acad Pediatr 9, 322-329.

4. Centers for Disease Control and Prevention (2009) Obesity prevalence among low-income, preschool-aged children United States, 1998-2008. MMWR Morb Mortal Wkly Rep 58, 769-773.

5. Trust for America's Health (2010) F as in Fat: How Obesity Policies are Failing America. http://healthyamericans.org/ reports/obesity2010/Obesity2010Report.pdf (accessed July 2012).

6. Institute of Medicine, Committee on Prevention of Obesity in Children and Youth (2004) Preventing Childbood Obesity: Health in the Balance [JP Koplan, CT Liverman and VI Kraak, editors]. Washington, DC: National Academies Press.

7. Institute of Medicine, Committee on Childhood Obesity Prevention Actions for Local Governments (2009) Local Government Actions to Prevent Childhood Obesity [L Parker, AC Burns and E Sanchez, editors]. Washington, DC: National Academies Press.

8. Wang Y \& Lobstein T (2006) Worldwide trends in childhood overweight and obesity. Int J Pediatr Obes 1, 11-25.

9. Centers for Disease Control and Prevention (2011) Obesity in K-8 students - New York City, 2006-07 to 2010-11 school years. MMWR Morb Mortal Wkly Rep 60, 1673-1678.

10. Dietz WH (2011) Reversing the tide of obesity. Lancet 378 , 744-746.

11. Narayan KM, Boyle JP, Thompson TJ et al. (2003) Lifetime risk for diabetes mellitus in the United States. JAMA 290, 1884-1890.

12. Boyle JP, Thompson TJ, Gregg EW et al. (2010) Projection of the year 2050 burden of diabetes in the US adult population: dynamic modeling of incidence, mortality, and prediabetes prevalence. Popul Health Metr 8, 29.

13. Olshansky SJ, Passaro DJ, Hershow RC et al. (2005) A potential decline in life expectancy in the United States in the 21st century. $N$ Engl J Med 352, 1138-1145. 
14. Rocchini AP (2011) Childhood obesity and coronary heart disease. N Engl J Med 365, 1927-1929.

15. Slater A, Bowen J, Corsini N et al. (2010) Understanding parent concerns about children's diet, activity and weight status: an important step towards effective obesity prevention interventions. Public Health Nutr 13, 1221-1228.

16. Rudolph H, Bluher S, Falkenberg C et al. (2010) Perception of body weight status: a case control study of obese and lean children and adolescents and their parents. Obes Facts 3, 83-91.

17. Jaballas E, Clark-Ott D, Clasen C et al. (2011) Parents' perceptions of their children's weight, eating habits, and physical activities at home and at school. J Pediatr Health Care 25, 294-301.

18. Rees R, Oliver K, Woodman J et al. (2011) The views of young children in the UK about obesity, body size, shape and weight: a systematic review. BMC Public Health 11, 188.

19. Yao NL \& Hillemeier MM (2012) Weight status in Chinese children: maternal perceptions and child self-assessments. World J Pediatr 8, 129-135.

20. Florin TA, Shults J \& Stettler N (2011) Perception of overweight is associated with poor academic performance in US adolescents. $J$ Sch Health 81, 663-670.

21. Frenn M, Heinrich A, Dohmen CS et al. (2011) What can parents do to reduce youth obesity? An initial study with a diverse sample. J Pediatr Nurs 26, 428-434.

22. Snethen JA \& Broome ME (2007) Weight, exercise, and health: children's perceptions. Clin Nurs Res 16, 138-152.
23. Brodsgaard A, Wagner L, Peitersen B et al. (2011) Maternal and child awareness and expectations of child overweight. Obes Facts 4, 297-304.

24. Binkin N, Spinelli A, Baglio G et al. (2011) What is common becomes normal: the effect of obesity prevalence on maternal perception. Nutr Metab Cardiovasc Dis (Epublication ahead of print version).

25. Sweeting H, West P \& Young R (2008) Obesity among Scottish 15 year olds 1987-2006: prevalence and associations with socio-economic status, well-being and worries about weight. BMC Public Health 8, 404.

26. Puhl RM, Luedicke J \& Heuer C (2011) Weight-based victimization toward overweight adolescents: observations and reactions of peers. $J$ Sch Health 81, 696-703.

27. Sonneville KR \& Gortmaker SL (2008) Total energy intake, adolescent discretionary behaviors and the energy gap. Int J Obes (Lond) 32, Suppl. 6, S19-S27.

28. Atlantis E, Barnes EH \& Singh MA (2006) Efficacy of exercise for treating overweight in children and adolescents: a systematic review. Int J Obes (Lond) 30, 1027-1040.

29. Wang YC, Gortmaker SL, Sobol AM et al. (2006) Estimating the energy gap among US children: a counterfactual approach. Pediatrics 118, e1721-e1733.

30. Perrin EM, Skinner AC \& Steiner MJ (2012) Parental recall of doctor communication of weight status: national trends from 1999 through 2008. Arch Pediatr Adolesc Med 166, 317-322.

31. Puhl RM, Peterson JL \& Luedicke J (2011) Parental perceptions of weight terminology that providers use with youth. Pediatrics 128, e786-e793. 